Methods: We reviewed the medical charts of the pediatric SLE patient in National Taiwan University Hospital from August 2015 to September 2019, and 50 SLE patients presented 185 episodes of suspicious activity or infection and received CRP, ESR, and Procalcitonin measurement were included. Time matched other laboratory parameters and clinical assessments were also collected. Episodes were divided into 4 groups: infected-active, infected-inactive, noninfected-active, and noninfected-inactive. Association of parameters with outcomes were predicted by generalized estimating equation. The receiver operating curve and the area under the curve were used to evaluate the diagnostic performance. We also used multinomial logistic regression model for nominal outcome, by setting noninfected-inactive group as the reference category.

Results: There were 7 males (14\%) and 43 females (86\%), with the mean ages $13.9 \pm 4.4$ years old. Most of the patients had renal $(72 \%)$ or mucocutaneous $(72 \%)$ involvement. The most common infection site was respiratory system (56\%). Multivariate GEE analysis showed Damage index(DI), SLEDAI-2k, neutrophil-to-lymphocyte ratio (NLR), hemoglobin, platelet, RDW-to-platelet ratio (RPR), and C3 are independent parameters for predicting SLE activity flare. Combination of these seven parameters resulted in a model with calculated AUC of 0.8964 and with sensitivity of $82.2 \%$ and specificity of $90.9 \%$. Multivariate GEE analysis showed DI, fever, CRP, Procalcitonin, lymphocyte percentage, $\mathrm{NLR}$, hemoglobin, and renal score in SLEDAI-2k are independent parameters for predicting acute infection. These eight parameters resulted in a model with calculated AUC of 0.7886 and with sensitivity of $63.5 \%$ and specificity of $89.2 \%$. We select a total of 10 variables (DI, SLEDAI-2k, Fever, Procalcitonin, lymphocyte percentage, NLR, hemoglobin, platelet, RPR, C3) to establish multinomial logistic regression, then predict four groups with accuracy of $70.13 \%$ for infected-active, $10 \%$ for infected-inactive, $59.57 \%$ for noninfected-active, and $84.62 \%$ for noninfected-inactive.

Conclusion: The proposed predictive calculator could be a useful tool for differentiation between activity flares and acute infections in pediatric SLE. Obtaining and combination of several parameters is effective and helpful to make appropriate judgement and treatment decisions for SLE patients.

References:

[1] Ceccarelli, F., et al., Assessment of disease activity in Systemic Lupus Erythematosus: Lights and shadows. Autoimmun Rev, 2015. 14(7): p. 601-8.

[2] Jung, J.Y. and C.H. Suh, Infection in systemic lupus erythematosus, similarities, and differences with lupus flare. Korean J Intern Med, 2017. 32(3): p. 429-438.

[3] Gensous, N., et al., Predictive biological markers of systemic lupus erythematosus flares: a systematic literature review. Arthritis Res Ther, 2017. 19(1): p. 238.

[4] Beca, S., et al., Development and validation of a risk calculator to differentiate flares from infections in systemic lupus erythematosus patients with fever. Autoimmun Rev, 2015. 14(7): p. 586-93.

[5] Sciascia, S., et al., Systemic lupus erythematosus and infections: clinical importance of conventional and upcoming biomarkers. Autoimmun Rev, 2012. 12(2): p. 157-63.

[6] Ospina, F.E., et al., Distinguishing infections vs flares in patients with systemic lupus erythematosus. Rheumatology (Oxford), 2017. 56(suppl_1): p. i46-i54.

[7] Ballinger, G.A., Using Generalized Estimating Equations for Longitudinal Data Analysis. Organizational Research Methods, 2004. 7(2): p. $127-150$.

Disclosure of Interests: None declared

DOI: 10.1136/annrheumdis-2020-eular.3987

\section{FRI0470 CARDIORESPIRATORY FITNESS IN JUVENILE IDIOPATHIC ARTHRITIS IN 6 - 17-YEAR-OLD CHILDREN- CROSS-SECTIONAL STUDY}

K. Räsänen ${ }^{1,2}, \mathrm{H}$. Lamberg ${ }^{2}$ on behalf of Timo Lakka ${ }^{3}$; Pekka Arikoski ${ }^{1 *}$ Eija Piippo-Savolainen ${ }^{1 \star} .{ }^{1}$ Kuopio, Department of Pediatrics, Kuopio, Finland; ${ }^{2}$ University of Eastern Finland, Kuopio, Finland

[ $\left.{ }^{1}\right]$ Department of Pediatrics and Adolescence, Kuopio University Hospital, University of Eastern Finland, Finland; $\left.{ }^{2}\right]$ University of Eastern Finland, Finland; $\left[{ }^{3}\right]$ Institute of Biomedicine, University of Eastern Finland, Finland; *contributed equally to this study

Background: Children with juvenile idiopathic arthritis (JIA) have been found to have reduced cardiorespiratory fitness and lower physical activity. Poor cardiorespiratory fitness is associated with a risk of cardiometabolic diseases.

Objectives: The aim of this study was to study the levels of cardiorespiratory fitness, respiratory function and hemodynamic responses during and after maximal cycle ergometer exercise test in children with JIA aged 6-17 years and compare the results with healthy controls.
Methods: Study group in this analysis consisted of 43 patients with JIA who were treated in Department of Pediatrics in Kuopio University Hospital, Finland and 40 healthy age- and sex matched controls. Maximal exercise tests were carried out with an electromagnetic cycle ergometer using a pediatric saddle module. Maximal workload per kilogram $\left(\mathrm{W}_{\max } / \mathrm{kg}\right.$ ) was used as a measure of cardiorespiratory fitness and was presented relative to bodyweight. In addition the peak values of $\mathrm{VO}_{2}$ per kilogram $\left(\mathrm{VO}_{\max } / \mathrm{kg}\right.$ ) were used as a measure of highest amount of oxygen that an individual can consume during exercise. Values of $\mathrm{VO} 2$ were collected from respiratory gases measured directly from breath by breath method and was presented relative to body weight.

Physical activity and sedentary behavior (minutes per day) was assessed by the PANIC (Physical activity and nutrition in children -study) Physical Activity Questionnaire which the participants filled.

Results: Statistical analyses were performed for 43 children with JIA and 40 controls. Mean age in JIA group was 12.09 years $(95 \% \mathrm{Cl} 11.04-13.14)$, and 11.72 years $(95 \% \mathrm{Cl} 10.52-12.93)$ in controls $(p=0.572)$. Mean body mass index for age (BMI) was $22.58 \mathrm{~kg} / \mathrm{m}^{2}(95 \% \mathrm{Cl} 21.54-23.62)$ in $\mathrm{JIA}$ and $18.95 \mathrm{~kg} / \mathrm{m}^{2}(95 \% \mathrm{Cl}$ 17.73-20.16) in controls ( $p<0.05$ ). In JIA group BMI was $19.18 \%$ higher compared to controls. Mean physical activity in JIA group was 94.11 minutes per day (95\% Cl 81.09-107.13), and 122.54 minutes per day $(95 \% \mathrm{Cl} 102.84-142.24)$ in controls, thus JIA group was $23.20 \%$ less physically active than controls $(p=0.015)$.

Mean $\mathrm{W}_{\text {ax }} / \mathrm{kg}$ was $2.65 \mathrm{~W} / \mathrm{kg}(95 \% \mathrm{Cl} 2.49-2.82)$ in $\mathrm{JIA}$ and $3.01 \mathrm{~W} / \mathrm{kg}$ $(95 \% \mathrm{Cl} 2.86-3.15)$ in controls thus $\mathrm{W}_{\text {max }} / \mathrm{kg}$ in JIA was $0.36 \mathrm{~W} / \mathrm{kg}(11.8 \%)$ lower than in controls, $(p=0.002)$. VO2 $2^{\text {max }} / \mathrm{kg}$ was $37.00(95 \% \mathrm{Cl} 33.96-40.84)$ $\mathrm{ml} / \mathrm{kg} / \mathrm{min}$ in $\mathrm{JIA}$ and $43.30(95 \% \mathrm{Cl} 40.79-45.82) \mathrm{ml} / \mathrm{kg} / \mathrm{min}$ in controls thus in JIA group mean VO2 $/ \mathrm{kg}$ was $6.3 \mathrm{ml} / \mathrm{kg} / \mathrm{min}(14.4 \%)$ lower than in controls $(p=0.001)$

Conclusion: Children with JIA were found to have significantly lower cardiorespiratory fitness. In addition, BMI in JIA patients was higher compared to healthy age- and sex-matched controls. Impaired cardiorespiratory fitness and highe BMI may predispose children with JIA to cardiometabolic comorbidities later in life. In addition to disease-control, more attention should be paid to maintaining good cardiorespiratory fitness and normal BMI in these patients already before adulthood.

\section{References:}

[1] M Nørgaard, M Twilt, LB Andersen \& T Herlin (2016) Accelerometry-based monitoring of daily physical activity in children with juvenile idiopathic arthritis, Scandinavian Journal of Rheumatology, 45:3, 179-187,

[2] Maggio, A.B.R., Hofer, M.F., Martin, X.E. et al. Reduced physical activity level and cardiorespiratory fitness in children with chronic diseases. Eur J Pediatr 169, 1187-1193 (2010)

[3] Bohr, AH., Fuhlbrigge, R.C., Pedersen, F.K. et al. Premature subclinical atherosclerosis in children and young adults with juvenile idiopathic arthritis. A review considering preventive measures. Pediatr Rheumatol (2016)14: 3.

Acknowledgments: Panu Karjalainen1, Timo Pitkänen1, Anneli Paloranta2, Kirsi Saastamoinen1

1 University of Eastern Finland 2 Kuopio university hospital, Finland

Disclosure of Interests: None declared

DOI: 10.1136/annrheumdis-2020-eular.675

\section{\begin{tabular}{|l|l}
\hline FRI0471 ADVERSE FACTORS OF COMORBID DISEASES \\
\hline
\end{tabular} DEVELOPMENT AT DIFFERENT VARIANTS OF JUVENILE IDIOPATHIC ARTHRITIS (JIA)}

N. Shevchenko ${ }^{1,2}$, L. Bohmat ${ }^{2,3}$, I. Bessonova ${ }^{2,3}$, V. Nikonova ${ }^{2} .{ }^{1}$ V.N. Karazin Kharkiv National University, Department of Pediatrics No 2, Kharkiv, Ukraine ${ }^{2}$ SI Institute for Children and Adolescents Health Care of NAMS of Ukraine, Department of Cardiorheumatology, Kharkiv, Ukraine; ${ }^{3}$ V.N.Karazin Kharkiv Nataional University, Department of Pediatrics, Kharkiv, Ukraine

Background: It is known that rheumatic diseases are the pathogenetic basis for the formation of many comorbid conditions, the most important of that are cardiovascular pathology, atherosclerosis, osteoporosis, chronic kidney disease and amyloidosis, chronic obstructive pulmonary disease. The start of the disease at an early age, the long-term duration of JIA, the use of basic immunosuppressive therapy lead to the possibility of the onset of the first signs of comorbid conditions in childhood.

Objectives: To study risk factors for the formation of damage of internal organs and systems in children with non-systemic JIA.

Methods: The case histories of 121 patients aged 7-18 years (mean age $11.0 \pm 0.3$ years) with polyarticular $(67.7 \%)$, oligoarticular $(14.88 \%)$ and uveitis-associated (17.35\%) JIA were studied, mainly of females $(73.5 \%)$. The age of the start of the disease was $5.9 \pm 0.4$ years, the duration of JIA at the time of analysis reached $67.1 \pm 4.3$ months. All children received basic methotrexate therapy (plus folic acid), short courses of NSAIDs. There are studied changes in the cardiovascular system (ECG, ultrasound, 6-minute walk test) 